\title{
CNC MACHINE TOOLS FOR LOW COST MICRO DEVICES MANUFACTURING
}

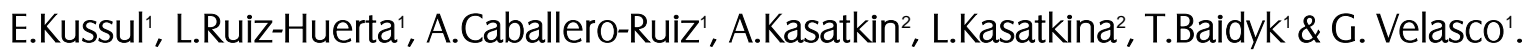 \\ ${ }^{1}$ Center of Applied Science and Technological Development, \\ National Autonomous University of Mexico \\ ${ }^{2}$ International Research and Training Center of Information Technologies and Systems, \\ National Academy of Sciences of Ukraine
}

Received: January $29^{\text {st }}$, 2002. Accepted: January $13^{h}, 2004$

\begin{abstract}
A new technology for production of low-cost micromechanical devices is proposed. This technology is based on concepts already known in conventional mechanics, used to produce a number of equipment of smaller sizes generation after generation. It is necessary to adapt each generation of equipment to the changes in physical behavior due to the decreasing scale. This technology is developed in the context of the microfactory creation. The main requirements for microequipment development are discussed. Also, the micromachine tool prototypes belonging to the first generation are developed and tested in the Laboratory of Micromechanics and Mechatronics of the Center of Applied Research and Technological Development, UNAM. The equipment characterization is done. The microfilter design and fabrication is described as an example of the practical application.
\end{abstract}

\section{RESUMEN}

En este trabajo se presenta una nueva tecnología para la producción de dispositivos micromecánicos de bajo costo, dentro del contexto de desarrollo de microfábricas. Ésta tecnología propone producir una serie de generaciones de equipo cada vez de menor tamaño, basándose en los conceptos ya conocidos de la mecánica convencional. Se describe también la necesidad de adaptar cada generación de equipo a los cambios de comportamiento físico originados por el decremento de escala. Los principales requerimientos para el desarrollo de microequipo son discutidos y unas micromáquinas herramientas pertenecientes a la primera generación de microequipo, desarrolladas en el Laboratorio de Micromecánica y Mecatrónica del Centro de Ciencias Aplicadas y Desarrollo Tecnológico, UNAM, son descritas y probadas. El diseño y fabricación de un microfiltro es utilizado como un ejemplo de la aplicación práctica.

KEYWORDS: Micromachine tool, Microfilters, Accuracy.

\section{INTRODUCTION}

A new technology for the production of low cost micromechanical devices is proposed. The technology is based on the application of microequipment, similar to conventional mechanical equipment, but of far smaller sizes. It allows the use of conventional technology in the mechanical treatment of materials and automatic assembly of mechanical and electronic devices for manufacturing micromechanical and microelectromechanical devices of submillimeter sizes. We shall term it "Micro Equipment Technology" (MET). MET will use microequipment for manufacturing commercial products and, in turn, the necessary microequipment units will be produced by MET. The decrease of the 
manufacturing cost of microdevices will be achieved on the basis of mass parallel production processes, which will be used in MET [1], instead of the batch processes used in Micro Electro Mechanical Systems (MEMS) [2].

Micromechanical and MEMS devices are widely used for different applications. The automotive and aerospace industry use MEMS for producing different sensors and actuators [3,4,5]. In adaptive optics and telecommunications MEMS are used for optical switches [6]. A very interesting application of MEMS is for displays based on arrays of micromirrors reflecting external light beams to corresponding pixels of the screen [7]. Based on MEMS, new components for radio-frequency (RF) electronics are designed [8]. MEMS permit improvements in the characteristics of heat exchangers [9].

MEMS are used widely in medicine [2,10], biotechnology [11], neurophysiology [2], etc. There are projects aimed to develop mobile microrobots [12].

At present, the base technology to produce micromechanical devices is lithography $[2,13]$. Up to $99 \%$ of commercial MEMS production uses this technology [2], but lithography makes it possible to produce only two-dimensional (2D) shape details. The production of three-dimensional (3D) shape details poses many problems. This is why many researchers try to use conventional methods for the mechanical treatment of materials to produce microdevices [2,1317]. For this purpose, they use precise and ultra-precise machine tools, because tolerances of microdetails must be very small. To increase the accuracy of machine tools for microdetail manufacture, it is necessary to miniaturize machine tools. Two main reasons for miniaturization of machine tools have been given in [13]. The first one is a decrease of heat deformation of machine tools with a decrease in their sizes. The second is a decrease of material consumption for machine tool production. In this case, more expensive materials with better properties can be used for machine tool manufacture.

There are other reasons for the miniaturization of machine tools; one reason is that the vibration amplitudes of small machine tools are lower than those of large machine tools, because the inertial forces decrease as the fourth power of the scaling factor, and the elastic forces decrease as the second power of the scaling factor [18]. Smaller machine tools demand less space and lower energy consumption.

A special project for microfactory creation based on miniature micromachine tools has been initialized in Japan [19]. In this project the microequipment, which is no larger than 2-10 times of the product size, was proposed. In [20] there is another estimation given about microequipment size. The work area of machine tool must not exceed the size of treated detail more than two times. It means that the overall sizes of machine tools for details of submillimeter sizes must not exceed a few millimeters. The method of such microequipment manufacture is proposed in [1]. It is necessary to produce sequential generations of microequipment of smaller and smaller sizes using previous generations for manufacturing the next ones. The first generation of the microequipment having dimensions 100$200 \mathrm{~mm}$ could be produced by conventional mechanical machine tools.

Each new generation of microequipment should be organized as a microfactory with high automation level. The final goal is to create fully automated desktop microfactories containing huge number of micromachine tools, microassembly devices and other microequipment units [21-23]. Such factory is to be supervised by an operator. In this case, the labor cost of microdevice production will be very small. If microequipment for such factories will be produced also by similar microfactories, its cost also will be very small. Microfactory creation is intended to dramatically save energy, space and resources at production plants by reducing the size of production machines to that comparable with the products.

In this paper two prototypes of micromachine tools of the first generation are described. Some results of their testing are presented. 


\subsection{The first prototype}

The main idea was to make the prototype as simple as possible, and to use a minimum of commercial components for scaling down the developed micromachine tool of future generations. The developed micromachine tool is used for turning, milling, drilling, and grinding. To change the type of work it is necessary to change tools and software programs. The prototype was tested in the turning mode.

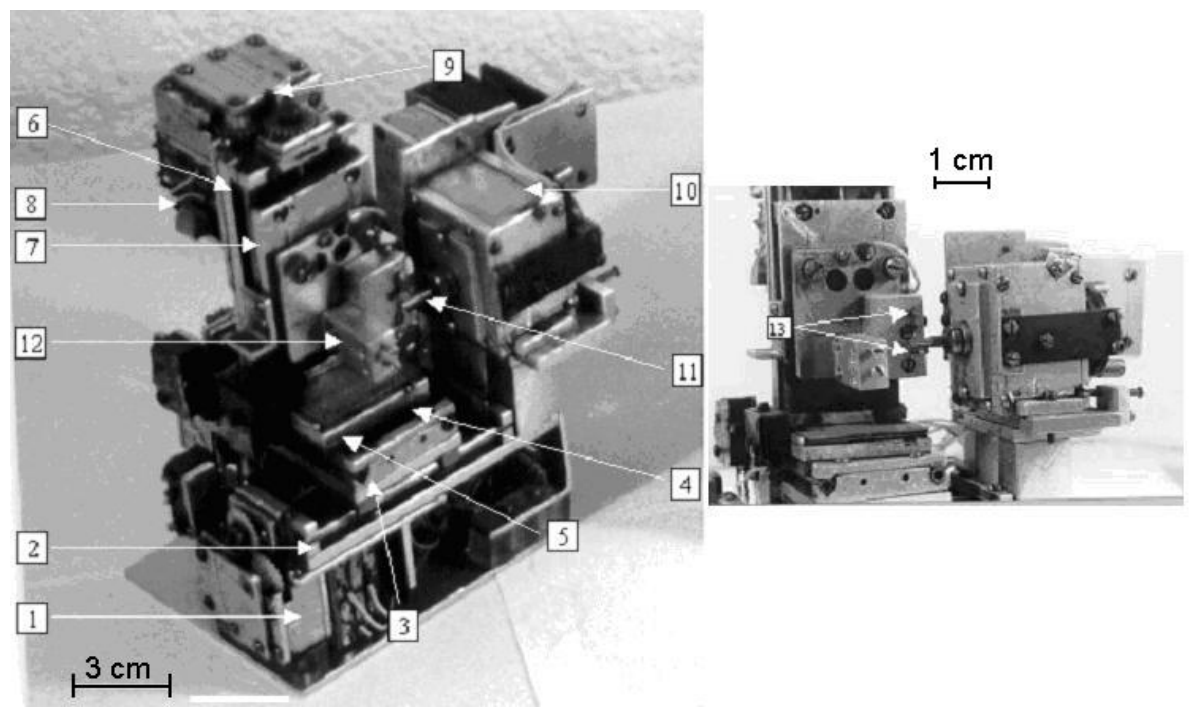

a)

b)

Figure 1. The first prototype of micromachine tool

The first prototype is shown in Fig. 1(a) and (b). On the base (1) the guides (2), (4), and (6), for three carriages (3), (5), and (7) are installed by the sequential scheme, i.e. each subsequent guide is installed on the previous carriage to provide translation movements along the axis $X, Y, Z$, respectively. The spindle case (10) with spindle (11) also are installed on the base. The drives for the carriages and for the spindle use stepping motors (8) with gearboxes (9). The spindle has a chuck to grip the workpiece for turning, a drill for drilling or a mill for milling. There is gripper (12) with a cutter and there are two parallel metal pins (13) for measurement of the turned workpiece diameter. For milling and drilling, the special gripper for the workpiece should be installed on the carriage (7).

The guides for the carriages were made build as round bars. This simplifies the production, assembly and scaling down of micromachine tools. The carriages (Fig. 2) were made as simple as possible. Each carriage contains a spring to eliminate the spaces between the carriage and the guides. Such a space is due to variations of guide diameter and thermal expansion of the carriage.

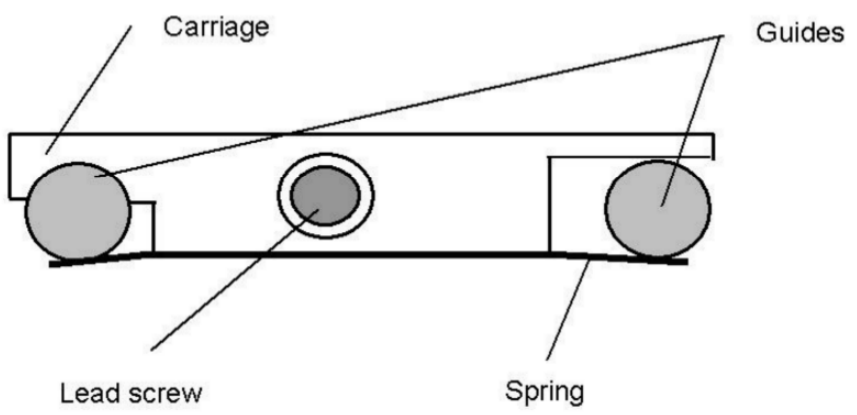

Figure 2. Design of carriage 
All other parts of the first prototype of the micromachine tool were also made according to criteria of low cost and scaling down.

We tested the first prototype in the following operations: the raw workpiece turning to the needed diameter, the shaft turning with different diameters, the screw turning, the groves cutting, the gear teeth cutting, the different details cutting from the metal bar.

The turning process is started from the home position procedure. All carriages are moved to their initial positions. Then all carriage movements are made on the basis of integral number calculations.

The raw workpiece could be installed in the spindle in different positions that is why it was necessary to find the position of the workpiece end. For this purpose the cutter tip was moved approximately to the spindle axis and then was moved up on the spindle (along the $Y$-axis) to obtain the electrical contact with the workpiece. At this moment the carriage (3) position (see Fig. 1) was stored. Thereafter the measurement of the workpiece diameter was performed. For this purpose the parallel pins of the carriage (7) were moved to the workpiece and located around the workpiece without contact. The workpiece was forced to rotate and the carriage was moved upwards to make contact between the lower pin and the workpiece. The contact was not stable, because the workpiece, as a rule, was installed eccentrically in the spindle. To take into account the instability of the contact, when the carriage after all was moved down, the last contact of the lower pin with the workpiece was fixed, and the corresponding carriage position was stored. The carriage continued to move down until the upper pin touched the workpiece. The distance between this position and the position of the last contact of the lower pin was calculated. This distance was subtracted from the distance between pins to get the diameter of the workpiece with possible beating due to the eccentricity of workpiece installation. This diameter was used later to determine the start position of the cutter in the turning process.

The cutter replacement or sharpening could change the position of its tip relatively to the cutter holder. In this case we need to determine the new position. For this purpose we place the cutter to the home position in the $x$-axis and moved it approximately up to the spindle level in the Z-axis. Then the workpiece was forced to rotate and the cutter was moved slowly along the X-axis up to contact with the workpiece. After that, the carriage (7) was moved down along Z-axis to the home position; and carriage (5) was moved forward along the X-axis for half of workpiece diameter. Thereafter the carriage (7) was moved up to make contact between the cutter and the workpiece. This position was stored. It permits us to say that the spindle axis is higher than the cutter tip on the half of workpiece diameter, and to install the cutter tip in the proper position to start the turning process.

The workpiece diameter measurements and the cutter position adjustments could be repeated during the turning process. These procedures permit the accuracy of the detail manufacture to be increased.

We have realized two ways of shaft producing. One way is to calculate the cutter positions during different shaft parts turning. The other way is to perform measurements of shaft diameter before final cutting. The first way gave errors of about 30 microns, the second - about 15 microns. Relatively low accuracy of turning and a way to improve it will be discussed in the next section.

To make a screw with the micromachine tool it is necessary to coordinate the step rate of the spindle with the step rate of carriage (5), which moves along the Xaxis. Sometimes in that case it is necessary to decrease the processing speed due to resonance in the stepping motors. The depth of screw grove is ensured by cutter position calculations.

For the gear teeth cutting we used an additional cutter with the cutting edge perpendicular to the cutting edge of the main cutter. The groves between teeth were made by translation movements of the additional cutter along the $Y$-axis and rotation of the spindle with a proper step rate. In Fig. 3 are shown some devices manufactured with the first micromachine tool prototype. 


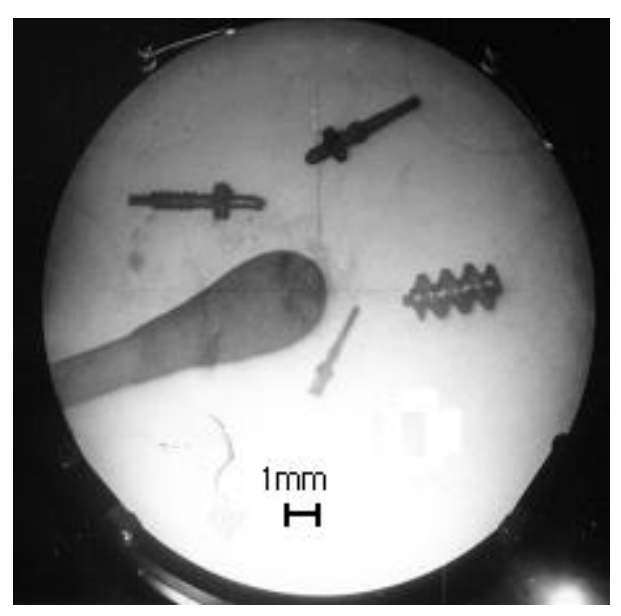

Figure 3. Devices manufactured with the first micromachine tool prototype, compared with a match head

\subsection{The second prototype}

The main advantages of the first prototype are the simplicity of its design and the easy manufacture of its components. But the first prototype had some drawbacks, which we tried to eliminate in the second prototype. The main drawback of the first prototype is its low rigidity.

To eliminate the spaces between the carriage and guides we used a spring. But in the case of a hard spring the movements of the carriages were not smooth; and in the case of a soft spring (which was finally used) the rigidity of the machine tool was insufficient. It was necessary to use a very small cutting depth and a small pitch. This increased the cutting time drastically. In many cases it was impossible to obtain a good level of accuracy. Some operations (like drilling) were difficult to perform.

To increase the rigidity of the carriages we manufactured the carriage guides more precisely and changed the springs to a hard support.

The second prototype is shown in Fig. 4.

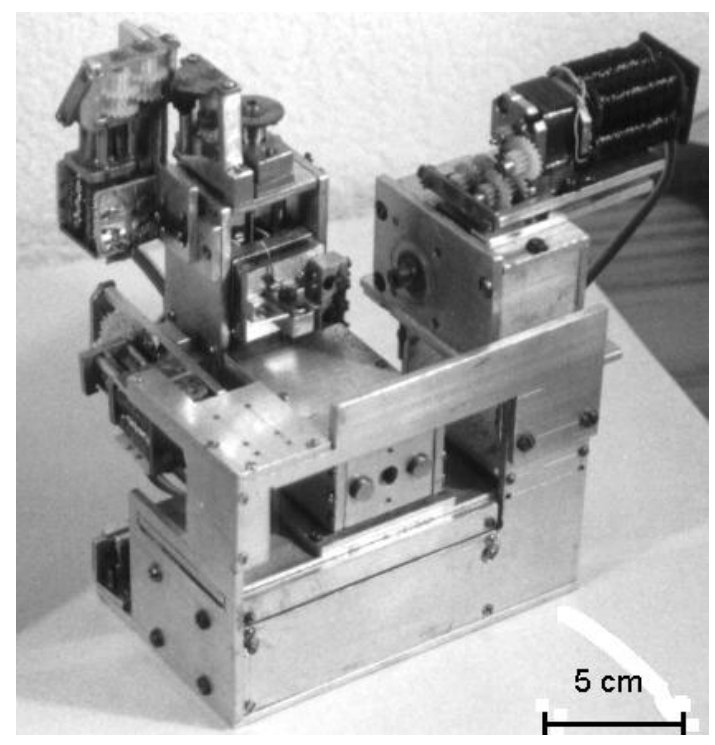

Figure 4. The second prototype of micromachine tool 
The parameters of both prototypes are presented in Table I

Table I. The parameters of the first and the second prototypes of the first generation micromachine tools.

\begin{tabular}{|ccc|}
\hline Parameters & The first prototype & The second prototype \\
\hline Width $(\mathrm{mm})$ & 80 & 85 \\
\hline Length $(\mathrm{mm})$ & 140 & 160 \\
\hline Height $(\mathrm{mm})$ & 150 & 130 \\
\hline Displacement $X(\mathrm{~mm})$ & 18 & 20 \\
\hline Displacement $Y(\mathrm{~mm})$ & 25 & 35 \\
\hline Displacement $Z(\mathrm{~mm})$ & 20 & 20 \\
\hline Resolution $(\mu \mathrm{m})$ & 2 & 1.87 \\
\hline
\end{tabular}

\section{CHARACTERIZATION OF THE SECOND PROTOTYPE OF MICROMACHINE TOOL}

In general, almost all the micromechanical devices are difficult to evaluate. The characterization of the second prototype of micromachine was made by indirect method; that is by the inspection of its own products (manufactured pieces).

We have used the following parameters for the characterization of the second prototype:

- Positional characteristics. Analysis of the axes resolution (linear displacement for each motor step). We also found backlash errors.

- Geometrical inspection. Geometrical analysis of the parameters of the pieces produced on our microequipment and a comparison of these with the design parameters of the pieces allows us to determine the accuracy characteristics.

The tests of the second micromachine prototype were made with the production of two test pieces with approximately known geometric characteristics. With the help of statistical analysis we determined the required parameters. For this analysis, twenty samples of each test piece were employed. Fig. 5 shows the samples of the test pieces.
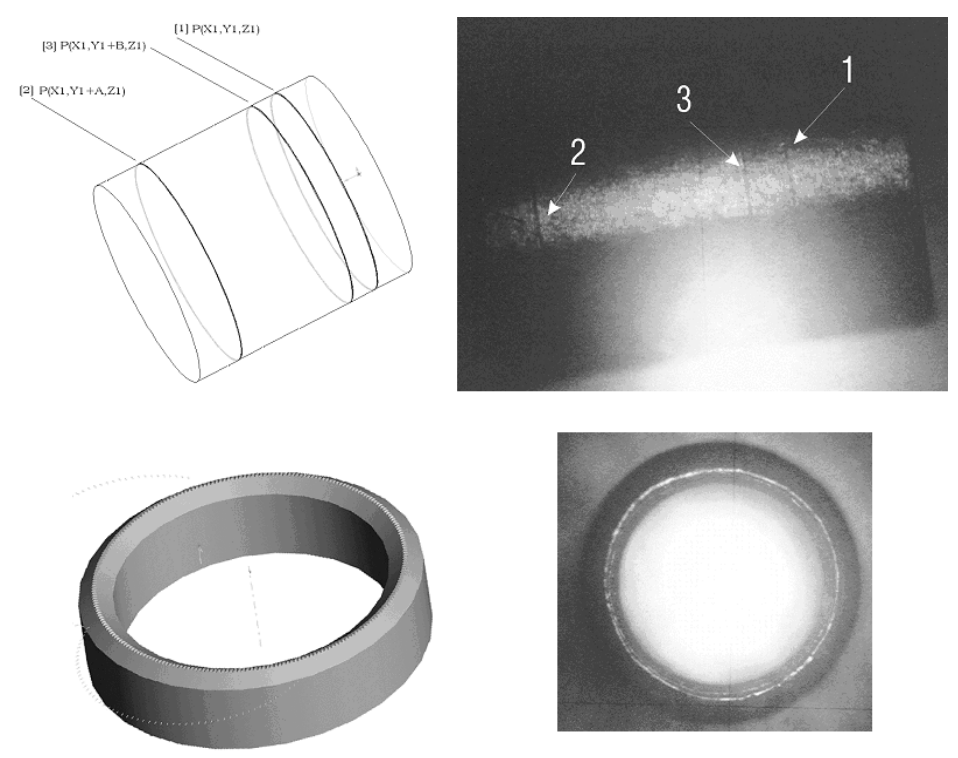

Figure 5. Test pieces employed in the second prototype evaluation 


\subsection{Positional characteristics}

One of the test pieces was a cylinder with three marks $(1,2,3)$. This was used to know the positional characteristics. The measured length was the distance between marks 1 and 2. This magnitude corresponds to the programmed displacement of 1050 motor steps.

The results of the measurements are: $X_{12}=1978 \mu \mathrm{m}, \sigma=6.07 \mu \mathrm{m}$. The standard deviation $\sigma$ gives information over $62.8 \%$ of the samples. In order to obtain a better sample range, it is necessary to triplicate the value of this result to get a sampling of $99.3 \%$, i.e. $3 \sigma=18.2 \mu \mathrm{m}$. Because of this, the error of this sample is Error $= \pm 18.2 \mu \mathrm{m}$.

This is the average error, and it can be interpreted as the error of the $Y$-axis displacement because all measurements were made in different positions on the axis. The displacement resolution for each step is $X_{\text {ors }}=1.88 \mu \mathrm{m}, \sigma=0.005$ $\mu \mathrm{m}$. In this case, the standard deviation is helpful only to give us an idea about the behavior of the resolution compared with the theoretical expectations for the deviation, but it is not a result that we can trust because the error is lower than the equipment accuracy. This standard deviation might be an estimation of the random error.

In order to quantity the backlash presented on the $Y$-axis, we measured the distance between marks $1-3$ of the testing pieces (Fig.6). The average backlash of the Y-axis is Backlash $=345.3 \mu \mathrm{m}, \sigma=7.8 \mu \mathrm{m}$.

There are several backlash error sources. The first source is related to the gearbox. The second and most important source is produced by the transmission and the carriage on each axis. The leading screw and the nut that is coupled to the carriage on each axis produce the third source. To eliminate the backlash influence we used unidirectional cutting and adaptive algorithms, which permitted us to know the real position of the cutter.

\subsection{Geometric inspection}

Microrings were designed for the geometric inspection. These rings were employed for a micromechanic filter (one of the applications of the proposed technology). The solid model and sample of the microring are shown in Fig. 5.

The drawing of the microring is presented in Fig.6.

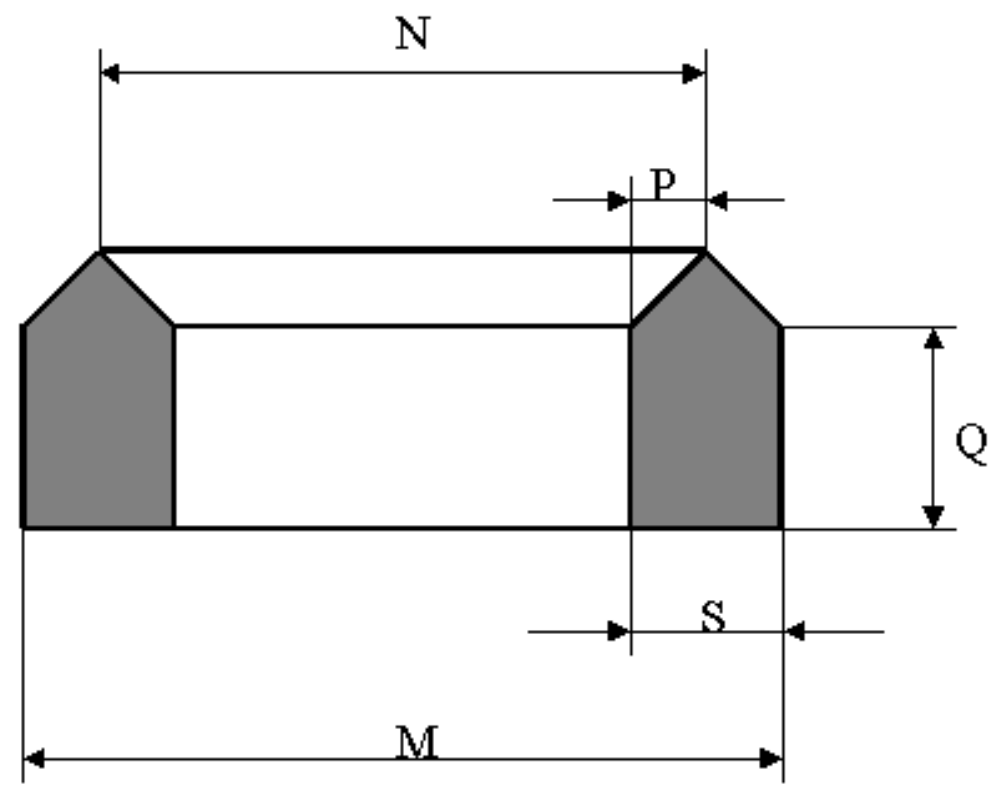

Fig. 6. The microring measurements 
$M$ - Exterior diameter of the microring base

$\mathrm{S}$ - Distance between the diameters (interior, and exterior of the microring base)

$\mathrm{N}$ - Diameter corresponding to intersection of conic surfaces

$\mathrm{P}$ - Distance between the conic surface intersection and the interior diameter of the cylindrical part of microring

Q - Height of the cylindrical part of microring

The measurement results are shown in Table II.

\section{Table II. Measurement results}

\begin{tabular}{|lcc|}
\hline \multicolumn{1}{|c|}{ Machining type } & $\begin{array}{c}\text { Average } \\
\text { measurement } \\
{[\mu \mathrm{m}]}\end{array}$ & $\begin{array}{c}\text { Average } \\
\text { error } \pm[\mu \mathrm{m}]\end{array}$ \\
\hline Cylinder machining $(\mathrm{M})$ & 1258.45 & 20.11 \\
\hline Drilling $(\mathrm{S})$ & 205.47 & 38.28 \\
\hline Cone machining $(\mathrm{N})$ & 981.30 & 62.19 \\
\hline Cone machining $(\mathrm{P})$ & 64.63 & 37.00 \\
\hline Cone machining $(\mathrm{Q})$ & 476.79 & 34.82 \\
\hline
\end{tabular}

Errors of the produced pieces depend on the machine tool, the instruments and the details machined. These errors allow the characterization of the micromachining center. The results obtained are satisfactory because the difference between the practical and theoretical results is sufficiently low. The theoretical results are calculated on the basis of the measurements of main components from which the machine tool was assembled. A comparison of practical and theoretical results is shown in Table III.

Table III. The comparison of the theoretical and practical results

\begin{tabular}{|lll|}
\hline Characteristics & Theoretical value $[\mu \mathrm{m}]$ & Measured value $[\mu \mathrm{m}]$ \\
\hline Displacement resolution & 1.875 & 1.88 \\
\hline Yaxis accuracy & \pm 18 & \pm 18 \\
\hline Backlash & 300 & 345.27 \\
\hline Machining accuracy & - & \pm 62 \\
\hline
\end{tabular}

\section{POSSIBLE APPLICATIONS OF MICROMACHINE TOOLS}

Many applications of micromachine tools could be considered as a consequence of the low cost, small space and energy consumption of such machine tools, and of the mass parallel automatic production process. The preferable area of application is the production of devices that contain huge numbers of micromechanical details of arbitrary 3D shape. We foresee that many types of new products will appear due to the low cost of such devices. As examples, we can mention large flat screens with mechanically driven image cells, mechanically driven random access memory, microbar assembly materials etc. Here we consider one application of such type microfilters for fine filtration of liquids and gases.

This problem relates to different branches of technological processes and environment protection. Fine filtration of air is needed for "clean rooms" used in microelectronics, medicine and other applications. Filtration of gases is needed for environment protection from pollution by power plants, transport vehicles and other devices which use fossil fuel. Fine filters have many applications in food industries, chemical industry, microbiology, etc. 


\subsection{Design of filters with a high relation of throughput to pressure drop}

The proposed filter contains a case, an inlet, an outlet, a flush valve and a huge number of microrings assembled into columns (Fig. 7). Liquid (or gas) goes through the inlet and comes into the internal space of the microring columns. After this, it goes through slits between microrings and comes out through the outlet. Hard particles are held back in the internal space of the microrings columns. To remove hard particles from the internal space of microrings, it is necessary to open the flush valve. Liquid (or gas) flow directed from the inlet to the flush valve will remove the sediment. Ultrasound vibration can be applied for better cleaning of the microring internal space.

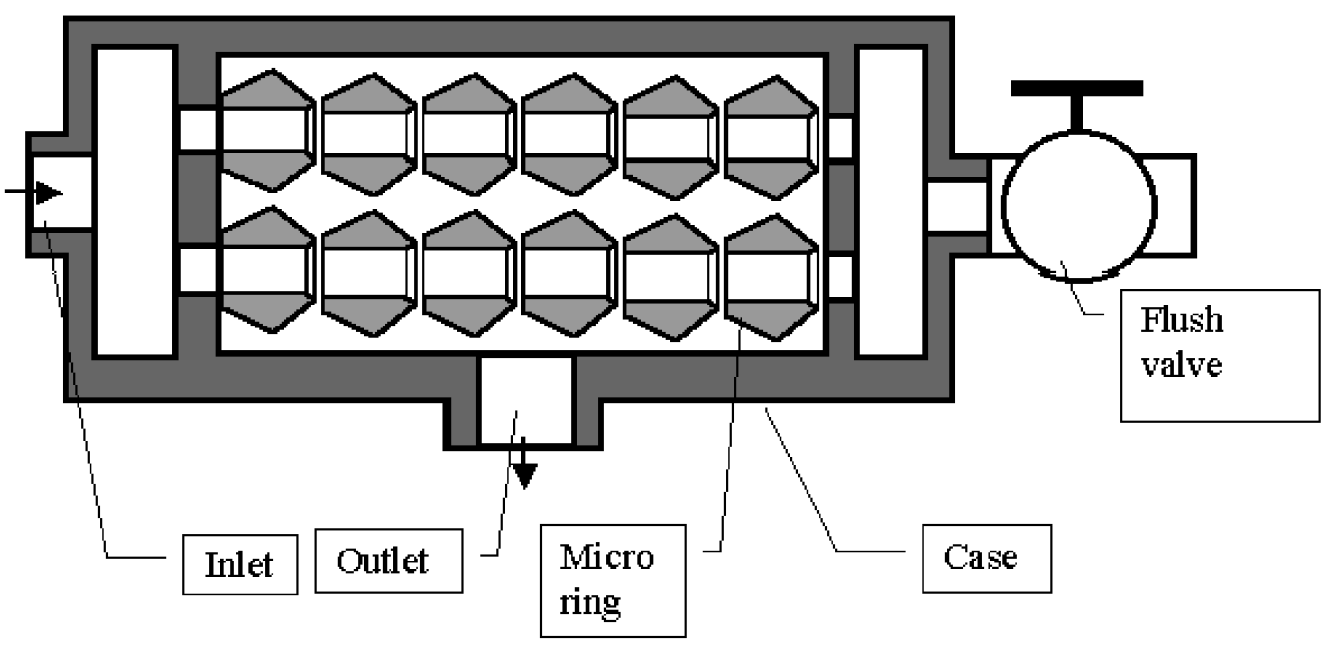

Figure 7. Filter design

To estimate the main parameters of the filter let us consider the slit between a pair of microrings (Fig. 8).

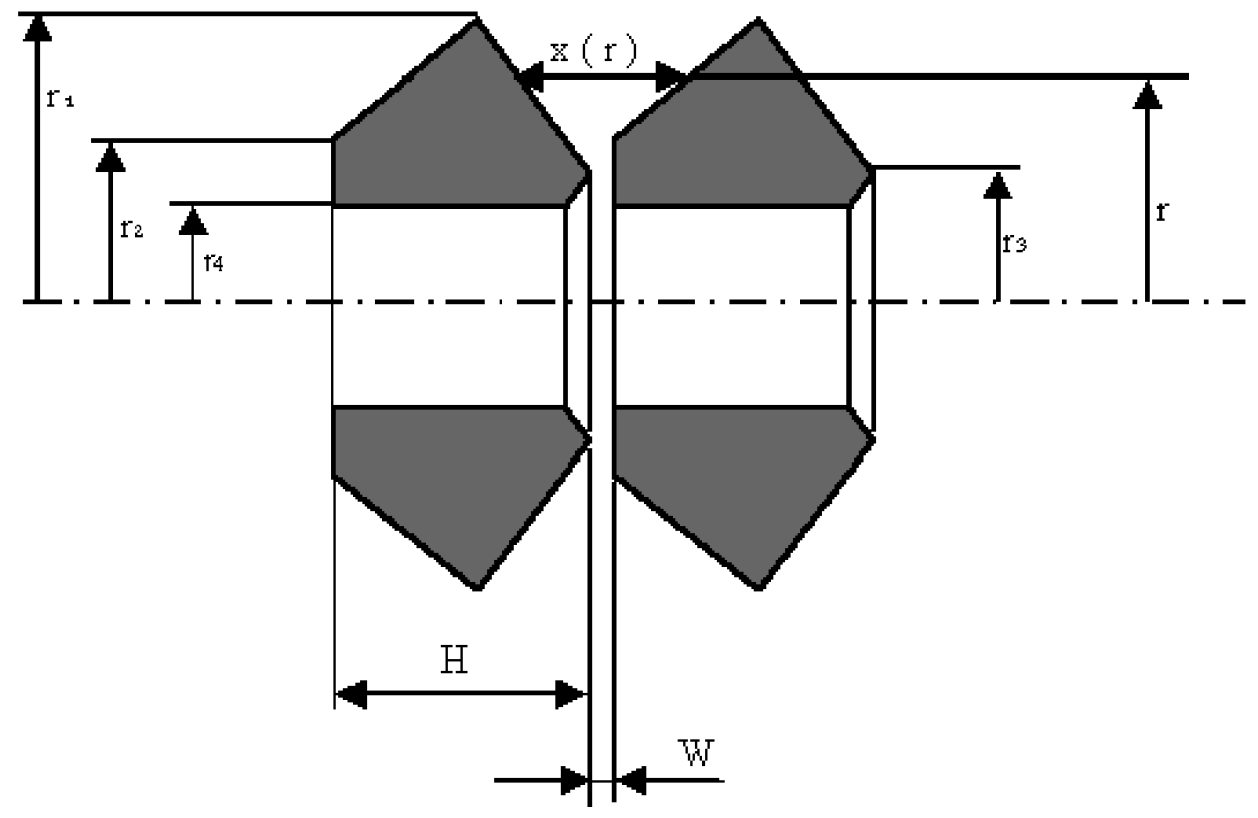

Figure 8. Arrange of rings 
Let the narrowest part of the slit has the width $W$ and the width of other parts of the slit can be calculated as:

$$
\begin{array}{cl}
x(r)=W+k_{1}^{*}\left(r_{3}-r\right) & \text { for } r_{3}>r \geq r_{1}, \\
x(r)=W+k_{2}^{*}\left(r-r_{3}\right) & \text { for } r_{2}>r \geq r_{3} \\
x(r)=W+k_{2}^{*}\left(r_{2}-r_{3}\right)+k_{3}^{*}\left(r-r_{2}\right) & \text { for } r_{1}>r \geq r_{2}
\end{array}
$$

The main parameters of the filters are the following: the size of arrested particles, relation of throughput to pressure drop, and the size (or the weight) of the filter. We have used a numerical model of the filtration process for the calculation of these properties.

To calculate the filter parameters it is necessary to know the hydraulic resistance of one slit between two microrings:

$$
G=P / Q
$$

where $G$ is the hydraulic resistance of one slit between two microrings, $P$ is the pressure drop in the slit, $Q$ is the flow rate in the slit. The hydraulic resistance of the section between radius $r$ and $r+d r$ can be calculated as

$$
d G=\frac{6 \mu}{\pi \cdot r \cdot x^{3}(r)} d r
$$

where $d G$ is the hydraulic resistance; $\mu$ is the viscosity coefficient; $r$ is the current radius (Fig.9); $x(r)$ is the current width of the slit at radius $r . x(r)$ is calculated by expressions (1-3) and then:

$$
G=\int_{r_{4}}^{r_{1}} d G
$$

We have determined $G$ by numerical integration of equation (6).

Hydraulic resistance of the slit depends on the shape of the microrings and on the distance between them.

3.2 The problems of fine filter manufacturing

Let us consider a filter that contains a total number of microrings equal to 50,000. The package, covers and other parts of filter have a very simple design and their manufacture is easy enough. The main problem of filter production is to manufacture microrings and install them into the drum grooves because of the huge number of microrings.

We propose to manufacture the microrings by the usual methods of material cutting, using cutting micromachine tools numerically controled by computer, and to install the micro rings into the filter, using the assembly micromanipulator numerically controlled by computer. For this, it is necessary to develop micromechanical technology to produce the components of the microfilter [1].

\subsection{The filter prototype manufactured by the second micromachine tool prototype}

For the second micromachine tool prototype test and the examination of the microfilter characteristics, we have made a microfilter prototype using the second micromachine tool prototype. A microfilter has one drum containing 12 columns with 10 microrings in each column. The internal diameter of each microring is $0.8 \mathrm{~mm}$, and the external diameter is $1.3 \mathrm{~mm}$. The height of each microring is approximately $0.6 \mathrm{~mm}$ (Fig. 9). 

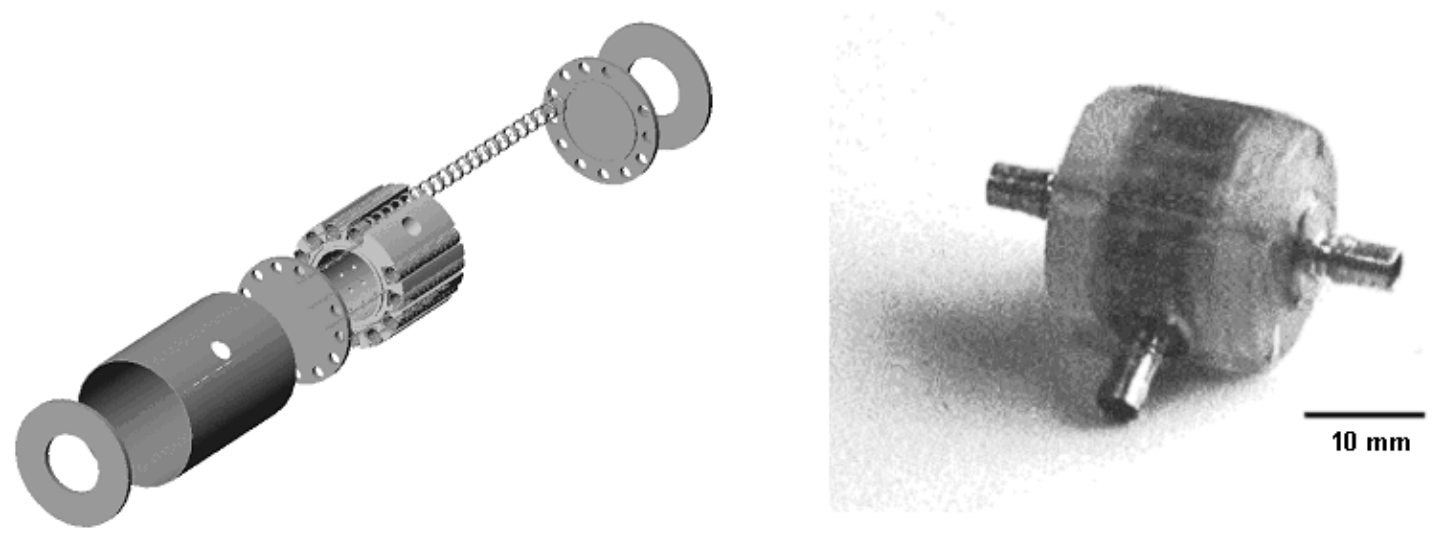

Figure 9. Filter assembly and prototype

\subsection{Case study}

To study the microfilter behavior we performed an experiment. It consisted in the measurement of the flow rate at three different pressures using pure water. The results obtained were compared with theoretical results, calculated by software. The final results are shown in Table IV, Fig. 10.

Table IV. Results of flow rate with different pressures

\begin{tabular}{|c|c|c|c|}
\hline & $\begin{array}{c}\text { Pressure } \\
{[\mathrm{Kpa}]}\end{array}$ & $\begin{array}{c}\text { Real Flow Rate } \\
{\left[\mathrm{mm}^{3} / \mathrm{s}\right]}\end{array}$ & $\begin{array}{c}\text { Theoretical Flow Rate } \\
{\left[\mathrm{mm}^{3} / \mathrm{s}\right]}\end{array}$ \\
\hline Experiment 1 & 3.237 & 2.33 & 2.9 \\
\hline Experiment 2 & 5.101 & 3.68 & 4.5 \\
\hline Experiment 3 & 7.063 & 5.09 & 5.6 \\
\hline
\end{tabular}

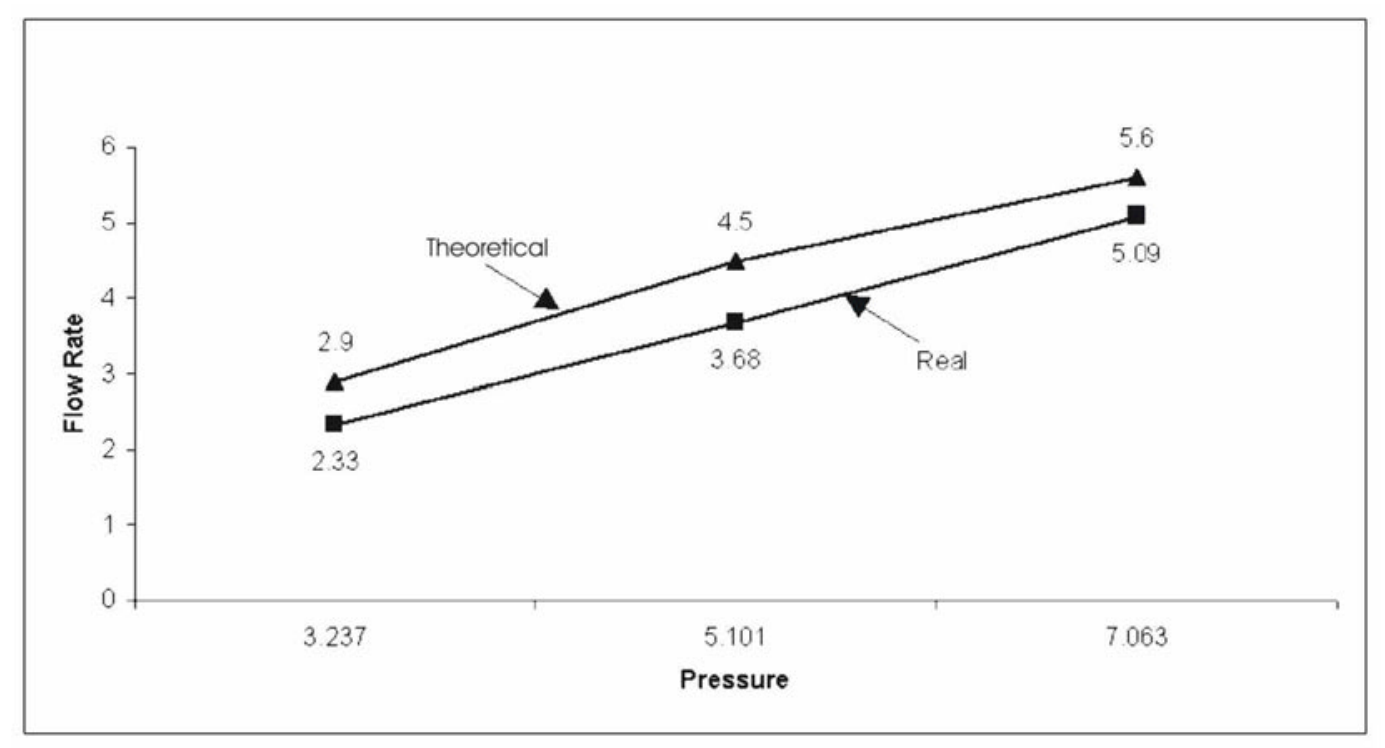

Figure 10. Flow rate vs. pressure in microfilter 


\section{DISCUSSION}

We have started the investigation of a new approach to micromechanical device fabrication, proposed in [1]. The approach assumes the production of microequipment (micromachine tools and micromanipulators) as sequential generations. Overall sizes of next generation microequipment must be smaller than the overall sizes of the previous generations. Untill now, we have made two prototypes of micromachine tools of the first generation.

The microring filter was produced using the second prototype of micromachine tool. This microring filter could be used for fine filtration of gases and liquids. It has good relation of flow rate to pressure drop and could be used for applications such as oil and fuel filtration and others.

The experiments with micromachine tools showed that for some products (as a microring filter) they have sufficiently good accuracy. But for other products (as microgears) the accuracy needs to be improved. There are some methods to improve the accuracy without significant increasing the machine tool cost. The first method is to use the adaptive algorithms which permit us to compensate the machine tool errors. These algorithms could be based on the different sensor information. The simplest information could be obtained from the electrical contact sensors. The preliminary experiments with adaptive algorithms based on contact sensors showed a significant increase of the machine tool accuracy. At present we work out the adaptive algorithms based on computer vision technology. We expect that this approach will enhance the accuracy of micromachine tool. The other method is to decrease the sizes of the micromachine tools. We will explore this method after designing the whole set of micromachine tools and micromanipulators, which are necessary to produce next generations of micromachine tools and micromanipulators.

\section{CONCLUSIONS}

We propose a new technology (MET) for producing micromechanical devices. For this purpose it is necessary to reduce the overall size of machine tools and assembly devices proportionally to the reduction of the devices to be produced.

These devices should be made by sequential generations of micromechanical equipment, of smaller and smaller sizes. Each new generation should be produced by previous generations. The experience in producing and evaluating prototypes of first generation micromachine tools, described here, shows that our goal is realistic. Conventional mechanical technologies could be transferred to the microworld by miniaturization of the corresponding technological equipment.

The microring filter produced by the second prototype of micromachine tool shows the effectiveness the proposed approach.

\section{ACKNOWLEDGEMENTS}

Acknowledgements to Laboratory of Metrology and Laboratory of Materials and Sensors (CCADET UNAM), in particular to José M. Saniger Bleza, José G. Bañuelos Muñetón, Rigoberto Nava Sandoval, Gerardo Ruiz Botello and José Sánchez Viscaíno, and for help in the manufacturing to Mr. Mario Rodríguez Segundo.

This work was supported by projects IN-118799, CONACYT 33944-U, NSF-CONACYT 39395A, PAPIIT IN-112102.

\section{REFERENCES}

[1] Kussul E.M., Rachkovskij D.A., Baidyk T.N. et al., Micromechanical engineering: a bases for the low-cost manufacturing of mechanical microdevices using microequipment. Journal of Micromechanics and Microengineering, No. 6, pp.410-425. 1996.

[2] Handbook of Microlithography, Micromachining and Microfabrication. V.2: Micromachining and Microfabrication, Ed. by P.Rai-Choundhury, SPIE Press, pp.622. 1997. 
[3] Ohlckers P., Jakobsen H., High Volume Production of Silicon Sensor Microsystems for Automotive Applications, in Digest of IEEE Colloquium on Assembly and Connection in Microsystems (No 1997/004), pp.8/1 - 8/7. 1997.

[4] Eddy D.S., Sparks D.R., Application of MEMS Technology in Automotive Sensors and Actuators, in Proceedings of the IEEE, V.86, Issue 8, pp.1747-1755. 1998.

[5] Madni A.M., Wan L.A., Micro Electro Mechanical Systems (MEMS): an Overview of Current State-of-the Art, in Proceedings of IEEE Aerospace Conference, V.1, pp.421-427. 1998.

[6] Comtois J.H., Michalicek M.A., Clark N., Cowan W., MOEMS for Adaptive Optics, In: IEEE/LEOS Summer Topical Meetings, Broadband Optical Networks and Technologies: An Emerging Reality/ Optical MEMS/ Smart Pixels/ Organic Optics and Optoelectronics. II/95-II/96. 1998.

[7] Johnson M.D., Hughes G.A., Gitlin M.L., Loebel N.G., Paradise N.F., Cathode Ray Addressed Micromirror Display, In Proceedings of the 13-th Biennial University/ Government / Industry Microelectronics Symposium, pp.158-160. 1999.

[8] Wu H.D., Harsh K.F. Irwin R.S. Wenge Zhang, Mickelson A.R., Lee Y.C., Dobsa J.B., MEMS Designed for Tunable Capacitors, In IEEE MTT-S International Microwave Symposium Digest, V.1, pp.127-129. 1998.

[9] Wu S., Mai J., Tai Y.C., Ho C.M., Micro Heat Exchanger by Using MEMS Impinging Jets, in Proceedings of the 12-th IEEE International Conference on Micro Electro Mechanical Systems, pp.171-176. 1999.

[10] Dohi T., Computer Aided Surgery and Micro Machine, in Proceedings of the 6-th International Symposium on Micro Machine and Human Science, pp.21-24. 1995.

[11] Katsura S., Hirano K., Yamaguchi A., Ishii R., Imayou H., Matsusawa Y., Mizuno A., Manipulation of Chromosomal DNA and Localization of Enzymatic Activity, in Proceedings of 32-th IAS Annual Meeting, Industry Applications Conference, V.3, pp.1983-1989. 1997.

[12] Sun L., Sun P., Qin X., Wang C., Micro Robot in Small Pipe with Electromagnetic Actuator, in Proceedings of the International Symposium on Micromechatronics and Human Science, pp.243-248. 1998.

[13] Micro Mechanical Systems: Principles and Technology, Ed. By T.Fukuda and W.Menz, Elsevier Science B.V., pp.268. 1998.

[14] Mazuzawa T., An Approach to Micromachining through Machine Tool Technology, in Proceedings of the $2^{\text {nd }}$ International Symposium Micro Machine and Human Science, Japan, pp.47-52. 1991.

[15] Friedrich C.R., Vasile M.J., Journal of Microelectromechanical Systems, No. 5, pp.33-38. 1996.

[16] Friedrich C.R., Kang S.D., Micro Heat Exchangers Fabricated by Diamond Machining, Precision Engineering, No. 16, pp.56-59. 1994.

[17] Yamagata Y., Higuchi T., Four Axis Ultra Precision Machine Tool and Fabrication of Micro Parts by Precision Cutting Technique, in Proceedings of the $8^{\text {th }}$ International Precision Engineering Seminar, France, pp.467-470. 1995.

[18] Ishihara H., Arai F., Fukuda T., IEEE/ASME Transactions on Mechatronics, V.1, pp.68-79. 1996.

[19] Some Micro Machine Activities in Japan, Report ATIP96.021. 1996.

[20] Kussul E.M., Baidyk T.N., Rachkovskij D.A., Talayev S.A., The Method of Micro Devices Manufacturing, Russian Patent N 2105652. 1997.

[21] Kussul E.M., Micromechanics as a New Area of Neural Network Applications, in Proceedings of EUFIT'97, vol.1, pp.521-523. 1997.

[22] Kussul E.M., Rachkovskij D.A., Artykutsa S.Y., Kasatkin A.M., Kasatkina L.M., Lukovich V.V., Talayev S.A., Adaptive Control System for Fully Automated Micromechanical Factory: The Problems and Possible Neural Network Solutions, in Proceedings of EUFIT'97, V.1, pp.524-527. 1997.

[23] Wunsch D.C., Kussul N.N., Kussul M.E., Adaptive Critic Design for Optimization of Micromechanical Factory Neural Control Systems, in Proceedings of EUFIT'97, V.1, pp.528-533. 1997. 
Authors Biography

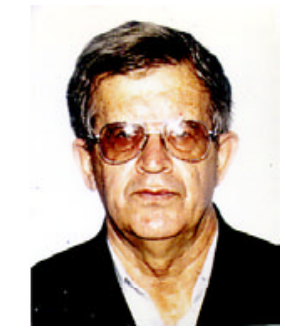

Ernst M. Kussul

Was born in May, 1938. He received his M.S. degree in mechanics from Leningrad Polytechnic Institute, Russia. From 1961 to 1965 he worked for Bryansk Machine Building Factory, Russia. He received the Ph.D. degree in mathematical logic and programming from the Institute of Cybernetics of Ukrainian Academy of Sciences. From 1967 to 1976 he worked with the Institute of Cybernetics of Ukrainian Academy of Sciences, as junior researcher, from 1976 to 1982, as senior researcher, from 1982 to 1988, as leading researcher. In 1982 he received D. Sc. degree in artificial neural networks from the Institute of Cybernetics of Ukrainian Academy of Sciences. From 1988 to 1998 he was head of the department of neural networks in the International Research and Training Center of UNESCO/IIP of Information Technologies and Systems. Since 1998 he is Researcher level " $\mathrm{C}$ " and head of the Laboratory of Micromechanics and Mechatronics in UNAM, Mexico. He has published over 100 scientific papers, authored and co-authored 2 books; he is author of 11 patents. He participated in international projects INTAS, and ISF. In 1992 he was invited to Japan as head of the international group to create neurocomputer B-512. In 1996 he was invited by National Science Foundation of USA to visit several MEMS laboratories to present his works. He was invited to present his works in England, France, Belgium, Slovakia, and Japan. He obtained the award of the Government of Ukraine in Science and Techniques in 1997. He is a member of the Mexican Academy of Technology. He participated in the program committee of several IJCNN conferences. His present research interests are micromechanics, mechatronics, neural networks, and pattern recognition.

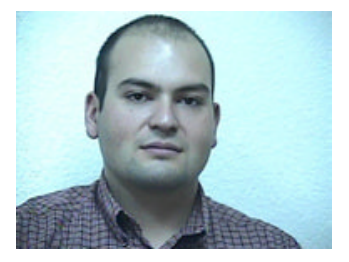

Leopoldo Ruiz Huerta

Was born in October 5th, 1974 in Mexico city. He earned degrees in: Mechanical Engineering (1998), Master Degree in Mechanical Engineering, fields of study: Mechanical design, electronics and micromechanics (2000). Awards: He obtains Honorific mention on bachelor and master degree. He works in the micromechanics and mechatronics laboratory at CCADET, UNAM. Now he is working in the designing and testing mechanisms of low cost and high performance, applied to micromechanics. In collaboration with other members of the laboratory, they develop new control methods and processes for micromanufacturig and microassembly. Characterization methods for micromechanics are studied too. 


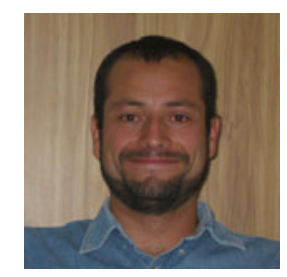

\section{Alberto Caballero Ruiz}

Was born Mexico City in 1974. He is an Electronic Engineer graduated in 1998 from the National University of Mexico, and got his master degree in Mechanical Engineering from the same university in 2000, obtaining Honorific Mention in both Bachelors and Master degrees. He works in The Micromechanics and Mechatronics Laboratory at CCADET, UNAM. His fields of study include electronics, mechanics and micromechanics. Awards: Honorific mention on bachelor degree and master degree.

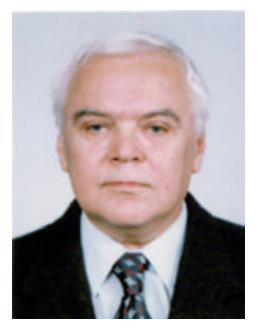

\section{Kasatkin Alexander M.}

Was born in Belgorod, Russia in May, $8^{\text {th }}, 1938$. He received his M. Sc. degree in Automatics and Telemechanics from Lviv Polytechnic Institute, Ukraine in 1962. He received the Ph.D. degree in Theoretical Cybernetics from the Institute of Cybernetics of Ukrainian Academy of Sciences in 1972. From 1964 to 1976 he was at the Institute of Cybernetics of Ukrainian Academy of Sciences as junior researcher, and from 1976 as senior researcher. From 1993 to 1996 he was chief of the Laboratory of Modelling of Neural Systems. In 1997 he worked as a senior researcher of the department of neural networks in the International Research and Training Centre of UNESCO/IIP of Information Technologies and Systems. He has published over 80 scientific papers, authored and co-authored 3 books. He got the award of the Government of Ukraine in Science and Techniques in 1997. He is a member of Association of Artificial Intelligence (Russia). His research interests are semantic neural networks, knowledge representation, decision making.

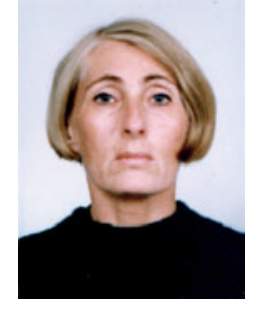

Kasatkina Lora $M$.

Was born in Dnepropetrovsk, Ukraine, in February, $21^{\text {th }}, 1940$. She received her M. Sc. degree in Gauge Engineering from Lvov Polytechnic Institute, Ukraine in 1962. She received the Ph.D. degree in Theoretical Cybernetics from the Institute of Cybernetics of Ukrainian Academy of Sciences in 1968. From 1964 to 1985 she worked for the Institute of Cybernetics of Ukrainian Academy of Sciences as junior researcher, and in 1985 as senior researcher. In 1997 she used to work as a senior researcher of the department of neural networks in the International Research and Training Centre of UNESCO/IIP of Information Technologies and Systems. She has published over 70 scientific papers, authored and co-authored 2 books. Her research interests are semantic neural networks, knowledge representation, understanding problems in Artificial Intelligence. 


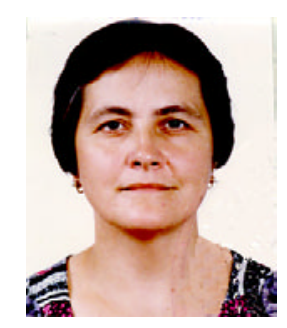

Tatiana N. Baidyk

Was born in March, 1954. She received the M. Sc. degree in Electrical Engineering from the Kiev Polytechnic Institute, Ukraine in 1977, and the Ph.D. degree in the control systems for mobile robots in 1983 from the Institute of Cybernetics of Ukrainian Academy of Sciences. From 1977 to 1995 she was at the Institute of Cybernetics of Ukrainian Academy of Sciences as post graduate student from 1977 to 1980, as junior researcher from 1980 to 1990 and as a senior researcher from 1990 to 1995. In 1994 T.Baidyk received D.Sci. degree in the area of neural networks from the Institute of Cybernetics of Ukrainian Academy of Sciences. From 1995 to 1999 she was a coordinator of the International Program of Education and Science in Ukraine, International Renaissance Foundation. From 1998 she was of the International Research and Training Centre of UNESCO/IIP of Information Technologies and Systems as leading researcher. Since 2001 she is Researcher level "A" in UNAM, Mexico. She has published over 80 papers, authored and co-authored 2 books, 3 patents and edited 8 other books. She participated in international projects INTAS and ISF, worked in 1992 in international group in Japan creating the neurocomputer B-512. Baidyk's present research interests are neural networks, pattern recognition, control systems, and industrial applications. She is a member of European Council of Artificial Intelligence, Association of Artificial Intelligence (Russia), member of Executive Committee of Neural Network Society (RNNS, Russia), member of Association of Developers and Users of Intelligent Systems (Ukraine).

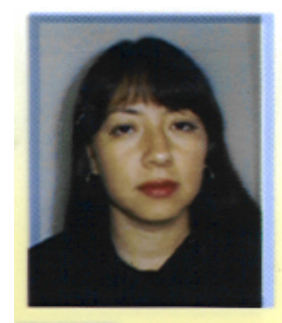

\section{Graciela Velasco}

Was born in Mexico City, in 1965. She graduated in Applied Mathematics and got a Master Degree in Physicomathematical Sciences from the State University of Donetsk of Ukraine (1995), PhD in Physico-Mathematical Sciences, specialty Theoretical Mechanics (2000) from the Institute of Applied Mathematics and Mechanics, National Academy of Sciences of Ukraine. She is researcher at the Centre of Applied Sciences and Technological Development of the UNAM. Her research interests include mathematical modeling and stability and control of mechanical system. 